\title{
Extraction of spatial-temporal rules from mesoscale eddies in the South China Sea based on rough set theory
}

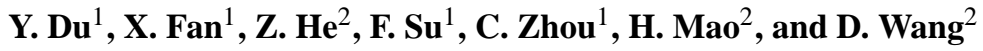 \\ ${ }^{1}$ State Key Laboratory of Resources and Environmental Information System, Institute of Geographic Science \\ and Natural Resources Research, Chinese Academy of Sciences, Beijing, 100101, China \\ ${ }^{2}$ Key Laboratory of Tropical Marine Environmental Dynamics, South China Sea Institute of Oceanology, \\ Chinese Academy of Sciences, Guangzhou, 510301, China
}

Received: 29 March 2011 - Published in Ocean Sci. Discuss.: 14 June 2011

Revised: 14 October 2011 - Accepted: 26 October 2011 - Published: 7 December 2011

\begin{abstract}
In this paper, a rough set theory is introduced to represent spatial-temporal relationships and extract the corresponding rules from typical mesoscale-eddy states in the South China Sea (SCS). Three decision attributes are adopted in this study, which make the approach flexible in retrieving spatial-temporal rules with different features. The results demonstrate that this approach is effective, and therefore provides a powerful approach to forecasts in the future studies. Spatial-temporal rules in the SCS indicate that warm eddies following the rules are generally in the southeastern and central SCS around $2000 \mathrm{~m}$ isobaths in winter. Their intensity and vorticity are weaker than those of cold eddies. They usually move a shorter distance. By contrast, cold eddies are in $2000 \mathrm{~m}$ and deeper regions of the southwestern and northeastern SCS in spring and fall. Their intensity and vorticity are strong. Usually they move a long distance. In winter, a few rules are followed by cold eddies in the northern tip of the basin and southwest of Taiwan Island rather than warm eddies, indicating cold eddies may be well-regulated in the region. Several warm-eddy rules are achieved west of Luzon Island, indicating warm eddies may be well-regulated in the region as well. Otherwise, warm and cold eddies are distributed not only in the jet flow off southern Vietnam induced by intraseasonal wind stress in summer-fall, but also in the northern shallow water, which should be a focus of a future study.
\end{abstract}

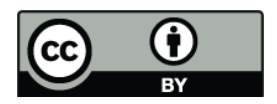

Correspondence to: C. Zhou (zhouch@1reis.ac.cn)

\section{Introduction}

The South China Sea (SCS: $2^{\circ} 30^{\prime}-23^{\circ} 30^{\prime} \mathrm{N}, 99^{\circ} 10^{\prime}-$ $121^{\circ} 50^{\prime} \mathrm{E}$ ) is the largest semi-enclosed marginal sea in the northwestern Pacific Ocean, as shown in Fig. 1. It has a large NE-SW oriented abyssal basin with greatest depth of $5567 \mathrm{~m}$. There is an approximate $3.5 \times 10^{6} \mathrm{~km}^{2}$ of total area with mean depth of $1212 \mathrm{~m}$. The SCS is well linked to the adjacent seas through several straits or channels, connecting to the Pacific Ocean through the Luzon Strait, to the Sulu Sea through the Mindoro Strait, to the East China Sea through the Taiwan Strait and to the Java Sea through the Karimata Strait and so on.

Under the combined influence of monsoon, Kuroshio intrusion, and complex topography, the SCS is characterized as an area with strong mesoscale activity (He et al., 2002). Located beneath the East Asian Monsoon system, the SCS has prevailing strong northeast winds in winter (October-next March), and southwest winds in summer (June-August); as a result, the near-surface circulation has an evident feature of seasonal variability (Qu, 2000; Wyrtki, 1961; Xu et al., 1982; Su, 2004). Hence, mesoscale variability shows a seasonal variation of flow pattern. The generation of eddies, as is well known, has a close relationship with wind forcing; positive wind stress curl induces a cyclonic eddy, and negative wind stress curl induces an anticyclonic eddy in the ocean. Sea surface height (SSH) is a useful indicator of upper-layer ocean circulation, being well able to reflect mesoscale signals. Zhuang et al. (2010) conclude that the intraseasonal SSH varibilities are induced by distinct mechanisms on the shelves and in the deep waters of the SCS:

Published by Copernicus Publications on behalf of the European Geosciences Union. 


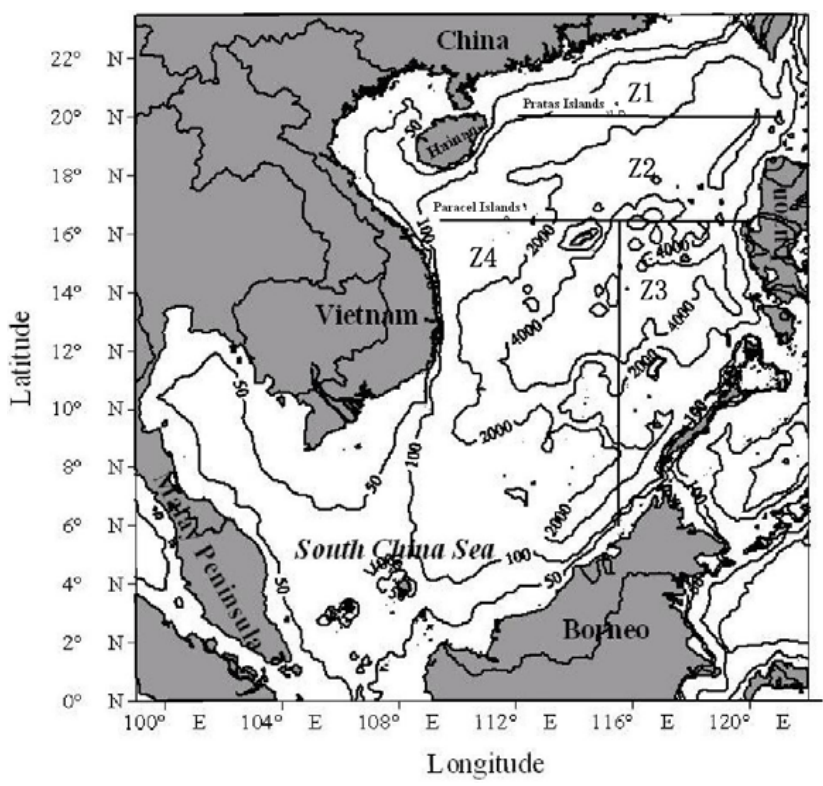

Fig. 1. Topography of the SCS. $\left(Z_{1}\right.$ : northeastern $S C S ; Z_{2}$ : central $\mathrm{SCS} ; \mathrm{Z}_{3}$ : southeastern $\mathrm{SCS} ; \mathrm{Z}_{4}$ : southwestern $\mathrm{SCS}$; solid lines are the boundaries of $\mathrm{Z}_{1}, \mathrm{Z}_{2}, \mathrm{Z}_{3}$ and $\mathrm{Z}_{4}$ ).

barotropic response to intraseasonal wind stress forcing in shallow water, and barotropic and baroclinic instabilities and eddy energy advection in deep water, with an exception offshore from Vietnam in summer.

On the other hand, mesoscale variability also has an interannual variation as a response to El Nino/Southern Oscillation (ENSO) in the SCS. Xiu et al. (2010) reveal that mesoscale eddy activities are not induced by the ENSO events directly, although interannual variabilities in $\mathrm{SSH}$ fields are highly correlated with ENSO (Xie et al., 2003; Liu et al., 2004; Wu and Chang, 2005; Fang et al., 2006; Wang et al., 2006). Previous works reveal that eddies are shed from strong currents such as the Gulf Stream and Kuroshio (Hurlburt and Thompson, 1980; Li et al., 1998; Hetland et al., 1999), and then generate prominent spatial-temporal variability in regional hydrography (Wu and Chiang, 2007). Observational results show that, in winter, there is an anticyclonic eddy shed from the Kuroshio loop due to an unstable Kuroshio meander in the northern Luzon Strait ( $\mathrm{Li}$ and $\mathrm{Wu}$, 1989; Jia and Liu, 2004); the eddy subsequently moves westward into the SCS (Li et al., 1998; Wang et al., 2000; Yuan et al., 2006). Direct views of eddy-shedding events can be provided by satellite remote sensing data (Yuan et al., 2007; Li, 2002; Su et al., 2002). Numerical studies also support this notion (Yang et al., 2000; Metzger and Hurlburt, 2001) and discuss eddy-shedding mechanisms (Jia et al., 2005). The previous studies reveal that mesoscale eddies propagate westward with a speed of $0.1 \mathrm{~m} \mathrm{~s}^{-1}$, the order of magnitude of the phase speed of baroclinic Rossby waves in the SCS (e.g. Wu et al., 2005; Wu and Chiang, 2007; Hwang et al.,
2004; Roemmich and Gilson, 2001; Hu et al., 2001; White, 2000; D. Wang et al., 2008). Topographic eddies can be induced by an eddy-shedding process resulting from the interaction between unstable rotating fluid and sharp topography in the SCS (Yuan and Wang, 1986; Hu et al., 2001).

Among methods of studying eddies, cruise observation is difficult and expensive, so that only sparse data can be achieved. Numerical modeling depends heavily on specific boundary conditions and also intensive computation. Remote sensing is good at extracting instantaneous state rather than continuous evolution of mesoscale eddies. Therefore, it is necessary to introduce a new approach to extract spatialtemporal rules from eddies efficiently in order to depict their distribution pattern in-depth and quantitatively.

Rough set theory is an approach to extract and represent the knowledge that can be derived from incomplete datasets with uncertainties (Miao and Li, 2008). Since rough set theory is available to analyze data with insufficient and incomplete knowledge, it has been applied in many traditional domains, including finance, medicine, telecommunications, vibration analysis, control theory, signal analysis, pattern recognition, and image analysis (Yasdi, 1996; Polkowski and Skowron, 1998; Polkowski et al., 2000; Skowron, 2001; Leung and $\mathrm{Li}, 2003$ ). In this paper, rough set theory is introduced to extract spatial-temporal rules from mesoscale eddies during November 2003-June 2009 in the SCS. In Sect. 2, we present the rough set theory and spatial-temporal relationships representation. Data sources and the spatialtemporal rules of mesoscale eddies in the SCS are described in Sect. 3. The findings are discussed in Sect. 4, followed by a conclusion in Sect. 5.

\section{Data and method}

\subsection{Data}

Raw data can be acquired from output of the US Naval Research Laboratory (NRL, http://www7320.nrlssc.navy.mil/ global_nlom32/scs.html) the NRL Layered Global Ocean Model (NLOM), including SSH, SST (Sea surface temperature) and surface current speed. The SSH data is assimilated from satellite data acquired by ENVISAT, GFO and JASON1 , etc. The SST data is assimilated from IR data with a temporal resolution of 1 day and a horizontal spatial resolution of $(1 / 32)^{\circ} \times(1 / 32)^{\circ}$. The SCS is divided into 4 zones $\left(\mathrm{Z}_{1}-\right.$ $\mathrm{Z}_{4}$, shown in Fig. 1), according to generating mechanisms of mesoscale eddies (Wang, 2004). We identify eddies in the SCS and track their evolution process from 5-yr-and-8month time series of SSH data during November 2003-June 2009 in accordance with the following four criteria:

1. There exist closed SSH contours (Wang, et al., 2003; Lin et al., 2007). 
2. The horizontal scale is not less than $100 \mathrm{~km}$ (Wang et al., 2003; Lin et al., 2007).

3. The eddy can be tracked over 20 days.

4. The SSH difference between center of an eddy and its outmost contour, intensity of an eddy $M$, is not less than $8 \mathrm{~cm}$ (Lin et al., 2007).

Wang et al. (2003) choose 30 days as the minimal lifetime of eddy processes, and Lin et al. (2007) choose 5 weeks. In this paper, shorter-lifetime eddies are able to be detected, owing to highly-resolved data. Eddy state is defined as a "timeslice" of an eddy process at one moment. In total, 391 typical mesoscale-eddy states, including 291 warm-eddy states and 100 cold-eddy states, are detected in this paper. Generally, one image represents one state, rather than more than one image represents one state. One of them with the corresponding modeling image is illustrated in Fig. $4 \mathrm{a}-\mathrm{c}$.

Initially, reliability of the modeling performance needs to be evaluated by comparing with hydrographic observation. SSHA (Sea surface height anomaly) was obtained from NLOM SSH fields during 2003-2009. AVISO merged temporal 7-day and spatial $(1 / 12)^{\circ} \times(1 / 12)^{\circ}$ sea level anomaly (SLA) observation is adopted to check the accuracy of NLOM SSHA. In Fig. 5a-e, several deterministic eddies of the SCS are shown, e.g. a warm eddy off the Luzon Strait (marked as red capital A), the eddy pair offshore from Vietnam (red capital D), in summer-fall, and its process of evolution are well reflected in NLOM SSHA. The warm eddy near Paracel Island (red capital C) and the west Luzon eddy (Qu, 2000; red capital B) are also well-reflected in the northern SCS. In addition, a cruise measurement was performed during 16 August-6 September 2008. Hourly current velocity was gathered by using ADCP (supported by South China Sea Institute of Oceanology, Chinese Academy of Sciences, China). Near-sea surface current speeds ( $38 \mathrm{~m}$ beneath) were selected to validate those at the corresponding positions simulated by NLOM. Comparison of the current speeds simulated by NLOM with cruise measurements is shown in Table 1 . Accuracy of current speed is calculated as

$\delta U=\left(1-\left|\frac{U_{\mathrm{NLOM}}-U_{\mathrm{ADCP}}}{U_{\mathrm{ADCP}}}\right|\right) \cdot 100 \%$

where $U_{\mathrm{NLOM}}$ is the surface current speed simulated by NLOM. $U_{\mathrm{ADCP}}$ is the $38 \mathrm{~m}$-layer current speed recorded by ADCP. $\delta U$ is the ratio of accuracy. $\delta U$ at 8 (out of 15) stations exceeds $70 \%$. Therefore, we consider the NLOM SSHA acceptable in the SCS.

\subsection{Rough set theory}

Rough set is a mathematical approach proposed by Pawlak (1982) to extract decision rules from a decision system, which is a special case of an information system. Formally, a decision system can be represented by the form
Table 1. Comparison of current speed derived from NLOM with cruise measurement.

\begin{tabular}{rccccc}
\hline Date & $\begin{array}{c}\text { Long. } \\
\left({ }^{\circ} \mathrm{E}\right)\end{array}$ & $\begin{array}{c}\text { Lat. } \\
\left({ }^{\circ} \mathrm{N}\right)\end{array}$ & $\begin{array}{c}U_{\mathrm{ADCP}} \\
\left(\mathrm{m} \mathrm{s}^{-1}\right)\end{array}$ & $\begin{array}{c}U_{\mathrm{NLOM}} \\
\left(\mathrm{m} \mathrm{s}^{-1}\right)\end{array}$ & $\begin{array}{c}\delta U \\
(\%)\end{array}$ \\
\hline 16 Aug 2008 & 115.5819 & 21.9792 & 0.1972 & - & - \\
17 Aug 2008 & 118.4670 & 22.0331 & 0.5448 & 0.3080 & 56.53 \\
18 Aug 2008 & 119.8457 & 21.3517 & 0.4631 & 0.3385 & 73.09 \\
19 Aug 2008 & 119.8736 & 19.0399 & 0.2419 & 0.2787 & 84.79 \\
20 Aug 2008 & 116.3940 & 18.1005 & 0.3667 & 0.3430 & 93.54 \\
21 Aug 2008 & 111.3139 & 17.3159 & 0.2210 & 0.2588 & 82.90 \\
22 Aug 2008 & 110.2487 & 17.3391 & 0.1031 & 0.0870 & 84.38 \\
25 Aug 2008 & 110.4957 & 18.0106 & 0.1632 & - & - \\
26 Aug 2008 & 112.8241 & 18.0117 & 0.3036 & 0.4579 & 49.18 \\
27 Aug 2008 & 116.5421 & 18.0086 & 0.3420 & 0.3385 & 98.98 \\
28 Aug 2008 & 114.2493 & 18.0073 & 0.3153 & 0.4996 & 41.55 \\
29 Aug 2008 & 111.5718 & 18.4941 & 0.2528 & 0.0750 & 29.67 \\
30 Aug 2008 & 111.3114 & 18.9107 & 0.1194 & - & - \\
31 Aug 2008 & 111.4607 & 19.2758 & 0.2247 & - & - \\
1 Sep 2008 & 113.2634 & 19.5524 & 0.3714 & 0.2787 & 75.04 \\
2 Sep 2008 & 115.8565 & 19.2557 & 0.2843 & 0.4996 & 24.27 \\
3 Sep 2008 & 115.7976 & 20.0368 & 0.3054 & 0.1828 & 59.86 \\
4 Sep 2008 & 117.0650 & 20.1009 & 0.2638 & 0.2172 & 82.34 \\
5 Sep 2008 & 115.6592 & 20.4859 & 0.2232 & 0.1362 & 61.02 \\
6 Sep 2008 & 113.8046 & 21.2015 & 0.1279 & - & - \\
\hline
\end{tabular}

$S=(U, C \cup D)$, where $U$ is a nonempty finite set of objects called the universe, $C$ is a nonempty finite set of attributes, and $D \notin C$ is the decision attribute. The elements of $C$ are condition attributes or simply conditions. The decision attributes may take several values, though binary outcomes are rather frequent (Komorowski et al., 1999). In this study, the universe $U$ may be the whole set of mesoscale-eddy cases in the SCS, and the decision attribute $D$ can be the place of origin, generating season or the type of mesoscale eddies. For example, we can associate the number 1 with a warm eddy, 0 with a cold eddy. Condition attributes in $C$ are the factors associated with spatial-temporal characteristics of mesoscale eddies, such as intensity, the place of origin, horizontal scale and relationships between a target eddy and its reference eddy ${ }^{1}$.

\subsubsection{Attribute reducts}

Rough set analysis aims at synthesizing an approximation of concepts from acquired data (Bai et al., 2010). There are some concepts that cannot be fully defined in a crisp manner by attributes at hand, e.g. mesoscale ocean eddies cannot be classified by their hydrographic features. Rough sets use upper and lower approximations to describe the uncertain concept.

\footnotetext{
${ }^{1}$ Reference eddy is defined as the nearest eddy to target eddy at a specific time. A circular area centered at the target eddy and with a radius of 60 nautical miles was screened to identify the eddy temporally occurring before and spatially closest to the target eddy. This specific eddy is deemed as the reference eddy.
} 
In rough set theory, attribute reducts is a key step. The basic idea is a classification (of the eddies in $U$ ) on the basis of attributes, using only attributes (in $C$ ) that help to refine the classification. We redundant attributes that do not distinguish between eddies in any "equivalence" class (i.e. eddies that are indistinguishable using all the retained attributes). There are usually several such subsets of attributes, and those that are minimal are called reducts (Komorowski et al., 1999).

The decision attribute $D$ induces a partition of the universe of objects $U$. Without any loss of generality, it is assumed that $V_{D}$ (decision values) is the set of $\mathrm{n}$ partitioning results according to the values of a geographical attribute $D\left\{v_{1}(D), \ldots, v_{n}(D)\right\}$, where $v_{i}(D)$ is said to be one of the partitioning results. The induced partition is therefore the collection of equivalence classes $X_{v_{1}(D)}, \ldots, X_{v_{n}(D)}$, called decision classes, where two objects are said to belong to the same decision class if they have the same result for the decision attribute: $X_{i}=\left\{x \in U \mid D(x)=v_{i}(D)\right\}$.

It is possible that two objects that are indistinguishable with respect to attributes $C$ may belong to different decision classes. The decision system $S$ is said to be inconsistent with respect to $C$ if this is the case and consistent otherwise.

The decision table is then simplified using the algorithm proposed by Pawlak (1991), which is briefly summarized as follows. The positive region of $D$ with respect to $C$, $\operatorname{POS}_{C}(D)$ is given by

$$
\operatorname{POS}_{C}(D)=\bigcup_{X \in U / D} \underline{C X}
$$

where $\operatorname{POS}_{C}(D)$ is a collection of all elements in $U$, which can be uniquely categorized into an equivalence class of $D$ by the partitioning $U$ according to values of attribute $C$. $X$ is any member of $U / D$ and $U / D$ represents an equivalence class of the decision attributes. $\underline{C} X$ denotes the lower approximation of $X$ with respect to $C$, which means $X$ cannot be exactly represented because it may include some objects which are indistinguishable based on the attributes $C$.

$\underline{C} X=\left\{x \mid[x]_{C} \subseteq X\right\}$.

Where $[x]_{C}$ denote the equivalence class of the $\mathrm{C}$ indiscernibility relations, which can also be denoted as $\operatorname{IND}(C)$ for simplicity, means that if $\left(x, x^{\prime}\right) \in \operatorname{IND}(C)$, then objects $x$ and $x^{\prime}$ reindiscernible from each other by attributes from $C$.

For an index $c$ in set $C(\forall c \in \mathrm{C})$, if

$\operatorname{POS}_{C}(D)=\operatorname{POS}_{C-\{c\}}(D)$

then $c$ is dispensable in $C$ with respect to $D$. Otherwise, $c$ is indispensable in $C$ with respect to $D$. If indices in $C$ are all indispensable with respect to $D$, then $C$ is totally independent with respect to $D$. Attribute reducts is a process to find a subset of $C$, which is totally indispensable with respect to $D$.

\subsubsection{Decision rule extraction}

Once the reducts are found, the rules are easily constructed by overlaying the reducts over the originating decision table and reading off the values. Let $X_{i}$ and $Y_{j}$ be the equivalence classes of $U / C$ and $U / D$, respectively. $\operatorname{des}\left(X_{i}\right)$ represents the description of equivalence class $X_{i}$, that is, the specific values of the condition attributes in set $C$. $\operatorname{des}\left(Y_{j}\right)$ refers to the description of equivalence class $Y_{j}$, that is, the specific values of decision attributes in $D$. Decision rules then can be generated and expressed as

$r_{i j}: \operatorname{des}\left(X_{i}\right) \rightarrow \operatorname{des}\left(Y_{j}\right) \quad Y_{j} \cap X_{i} \neq \varnothing$

Both the certainty and coverage factors for each specific rule are calculated to determine whether the rule is essential or not (Pawlak, 2001). The certainty factor measures how likely the result (derived from a specific rule) is correct. The certainty factor is the proportion of instances in the database following both the condition attributes and the equivalence class of the decision attribute. For example, it means for the same region of the condition attribute space, how many of the instances in the database lead to the same class in the decision attribute. It can be given by

$\alpha=\left|X_{i} \cap Y_{j}\right| /\left|X_{i}\right| \quad 0<\alpha<1$

A high value of $\alpha$ for a specific rule indicates that, if the condition attributes satisfy the rules, the decision results are more likely to be correct.

The coverage factor is defined as

$\beta=\left|X_{i} \cap Y_{j}\right| /\left|Y_{j}\right| \quad 0<\beta<1$

which represents, to some extent, the condition attributes satisfying the rules for a specific result. The value 1 indicates that, for any result, the condition attributes completely satisfy the rules. The lower the value, the lower probability the attributes may observe the rules. The certainty and coverage factors are then calculated for all rules which were generated from the reducts of set $C$. Only those rules (thereby the corresponding spatial relations) with certainty and coverage factors greater than a preset threshold are accepted.

In the above, it is assumed that the values of attributes are discretised data. If the attribute values are continuous, they should be discretised before hand. Over the years, many discretization algorithms have been proposed and tested to show that discretization has the potential to reduce the amount of data while retaining or even improving predictive accuracy. Current dominant discretization approaches generally fall into 2 categories: non-supervised and supervised. Nonsupervised approaches mainly employ equal-frequency and equal-interval algorithms. Supervised approaches mainly employ Entropy (MDLP - the minimum description length principle), Naive, and Semi-Naive algorithms (Fayyad and Irani, 1992, 1993), which take decision-making information into consideration and have a better discretization effect. 


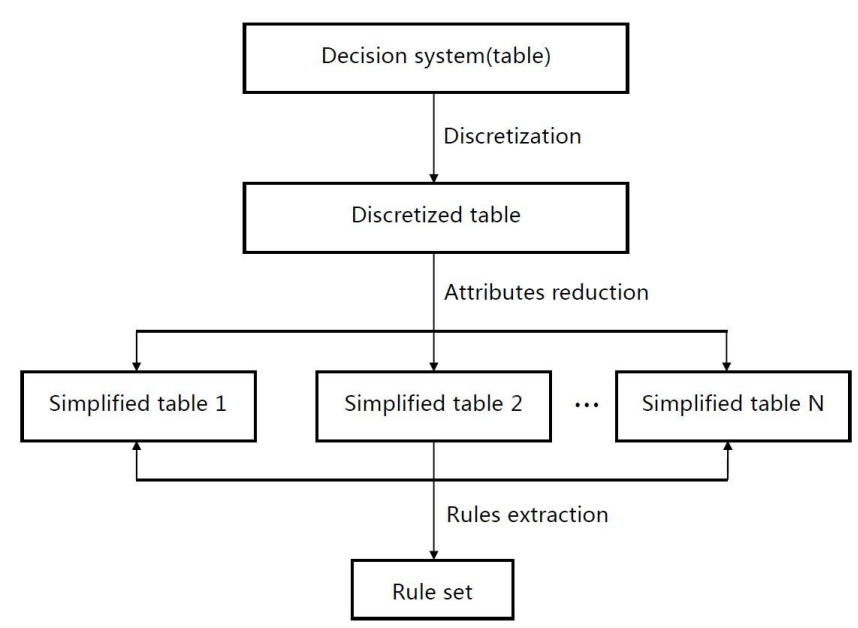

Fig. 2. Flowchart of the procedure for representing spatial-temporal relationships among mesoscale eddy states.

\subsubsection{Application of rough set theory to mesoscale ocean eddies}

Considering rough set theory does not need prior information in analyzing data; it can derive a classification or decision rules according to the knowledge reducts procedure. Hence, rough set theory can mine the objective and inherent rules implicit in the data. Given that the dynamic mechanisms of mesoscale eddies are still not grasped completely, our study adapts rough set theory to extract spatial distribution regularities of ocean eddies from highly-resolved ocean modeling data in quantity.

The whole process to extract spatial-temporal rules from mesoscale eddies by using rough sets can be divided into three steps (Fig. 2): (1) construct a decision information system based on the data at hand; (2) find minimal reducts of condition attributes; (3) generate rules according to the reducts.

In the first step, spatial-temporal relationship indices should be transformed from original data, which are then imported into the decision table. This step is crucial when rough set theory is used in spatial analysis of eddies. Many spatial attributes are continuous variables. Under such circumstances, the continuous attributes should be discretized before performing rough set analysis. In our study, a boolean algorithm was chosen to discretize the continuous attributes. A Boolean reasoning algorithm was first proposed by Nguyen and Skowron (1995). The algorithm operates by first creating a Boolean function from the set of candidate cuts, which can be the sets of mean value of any two different values in numerical attributes, and then computing a prime implicant of the function. A prime implicant of the function is an implicant that cannot be covered by a more general (more reduced - meaning with fewer literals). The subset of candidate cuts found by Boolean reasoning is a minimal set

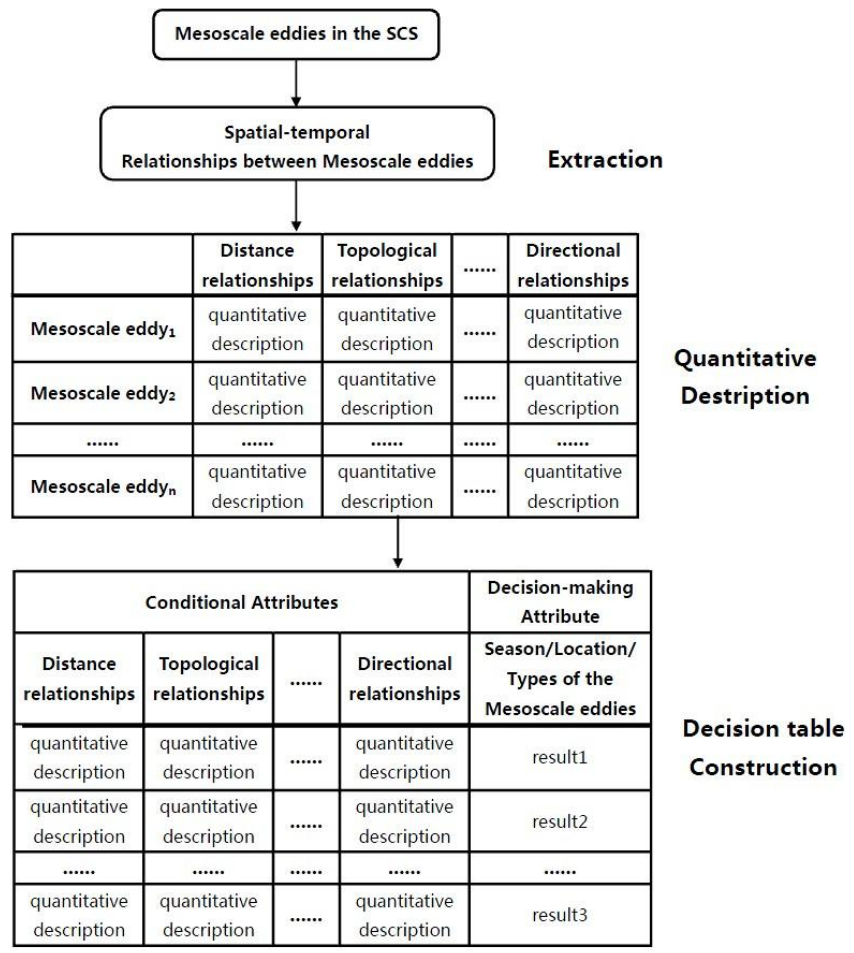

Fig. 3. Flowchart of major analysis steps based on the rough set theory.

of candidate cuts that preserves all discernibility inherent in the decision system (Skowron, 1995). It is used to discretise the decision table and a genetic algorithm is then applied to simplify and extract decision rules from relations between eddy attributes (Qhrn, 1999).

In the next step, as is described in Sect. 2.1, finding reducts is used as the attribute selection method. Not all attributes transformed or collected in the first step are the key factors that are related to the decision attribute. So it is important to select attributes that are in close relation to the decision.

Finally, spatial-temporal relationship rules of eddies in the SCS are generated from the reducts by overlaying the reducts over the originating decision table and reading off the values. The certainty and coverage factors of each specific rule are then calculated (Wang, 2001).

We present the detailed procedures to represent spatialtemporal relationships of mesoscale eddies, in view of the importance of the first step. As illustrated in Fig. 3, the procedures as follows:

1. Identify and select spatial-temporal relationships among eddies based on prior knowledge. For example, the distance between the target eddy and the nearest one which is generated most recently, or distance between the target eddy and the mainland coastline, can be selected as a specific relationship for investigation. 

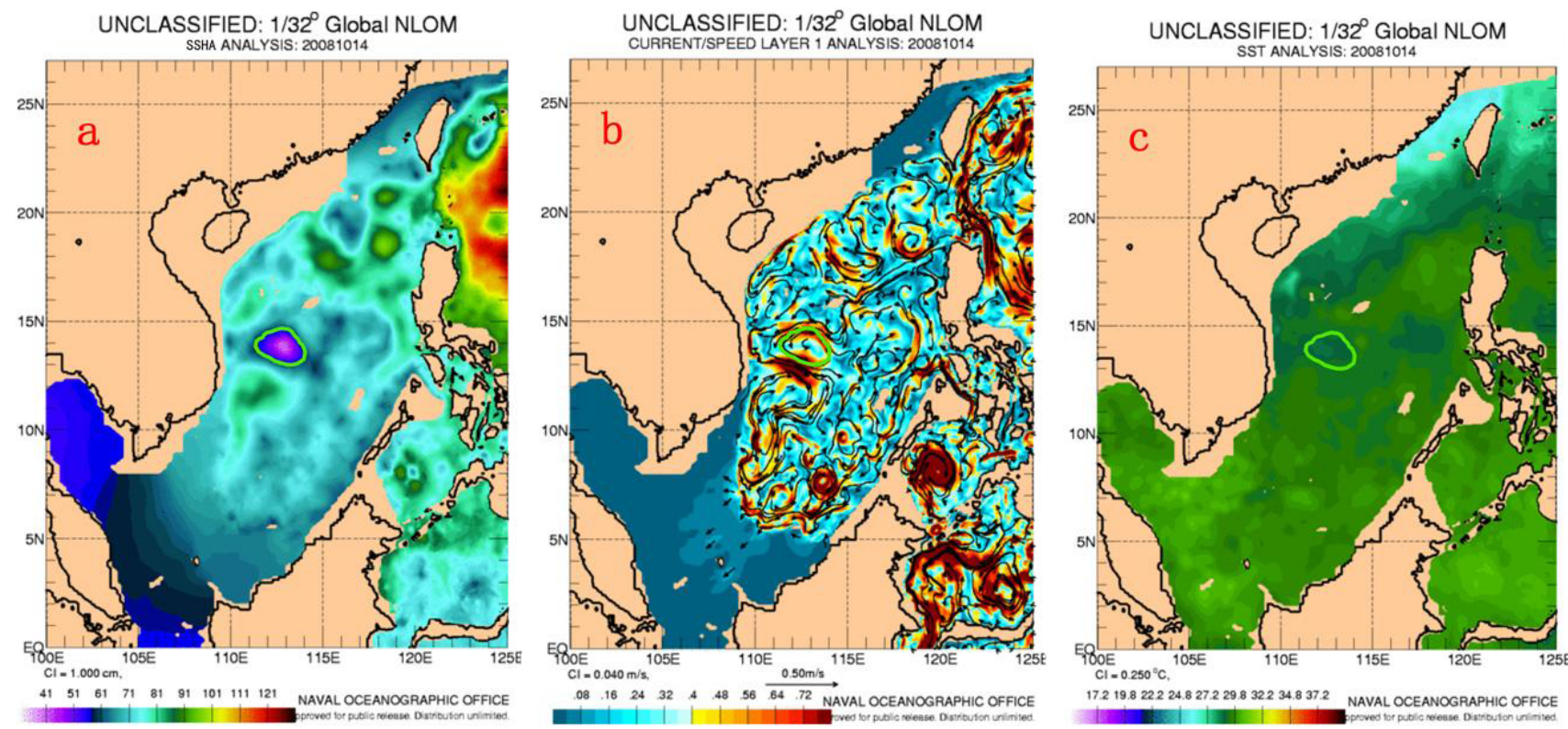

Fig. 4. Sketch map of a mesoscale eddy in the SCS (outlined by bright green contour).

2. These relationships are then described by a series of quantitative indices. For example, the RCC- 8 model (Randell et al., 1992; Randell and Cohn, 1989) can be used to describe the topological relationship among eddies. The topological relations record the relationships in space such as connectivity, intersection and adjacency among objects.

3. Decision tables are constructed with each row representing a case of an eddy, while columns record condition and decision attributes. The values in each row, except for the decision attributes, are the quantitative indices which are derived from spatial-temporal relationships.

According to the previous studies, two types of attributes of eddies are considered in this paper. One is their own characteristic attributes; another is features of spatial-temporal relationships. In total the attributes including:

1. Place of origin (Zone). According to generating mechanisms of mesoscale eddies, the SCS is divided into 4 zones: northeastern, central, southeastern, and southwestern zones (Wang, 2004), as shown in Fig. 1.

2. Generating season (Time). Spring is from March to May, summer from June to August, fall from September to November, and winter from December to next February.

3. Type of eddy (Type): warm or cold eddy.

4. Intensity of eddy $M$ (Intensity): SSH difference in metres between the center and the periphery of an eddy.
5. Vorticity (Vorticity) with an approximation of the relative vorticity of a eddy:

$\varsigma=\frac{\partial v}{\partial x}-\frac{\partial u}{\partial y} \approx \frac{8 g M}{f D^{2}}$

where $\varsigma$ is eddy's vorticity in $\mathrm{s}^{-1}, M$ eddy's intensity, $D$ eddy's diameter. The Coriolis parameter $f$ is $10^{-4} \mathrm{~s}^{-1}$, and the acceleration of gravity $g$ is $9.80 \mathrm{~ms}^{-2}$.

6. Horizontal scale of the eddy (HorizontalScale) in metres: the average of the major axis and the minor axis of an enclosing ellipse.

7. Temperature at the center of an eddy (CentralTemp) in Celsius degree.

8. Difference of temperature between the center and the periphery of an eddy (TempDiff) in Celsius degree.

9. Mean depth (Depth) in metres: the mean water depth at the center of an eddy.

10. The Euclidean distance (Distance) in metres from the geometric center of a target eddy to its reference eddy.

11. Directional relationship (Direction) to the reference eddy. In all eight directions are considered, involving north $(\mathrm{N})$, northeast $(\mathrm{NE})$, east (E), southeast (SE), south (S), southwest (SW), west (W) and northwest (NW). 
Table 2. Decision table constructed from spatial-temporal relationships of mesoscale-eddy states in 4 zones of the SCS.

\begin{tabular}{|c|c|c|c|c|c|c|c|c|c|c|c|}
\hline \multicolumn{11}{|c|}{ Condition attribute } & \multirow{2}{*}{$\begin{array}{l}\begin{array}{l}\text { Decision } \\
\text { attribute }\end{array} \\
\begin{array}{l}\text { Origin } \\
\text { place }\end{array}\end{array}$} \\
\hline Time & Type & $\begin{array}{l}\text { Intensity } \\
(\mathrm{m})\end{array}$ & $\begin{array}{l}\text { Vorticity } \\
\left(\times 10^{-6} s^{-1}\right)\end{array}$ & $\begin{array}{l}\text { Horizontal } \\
\text { scale } \\
(\mathrm{km})\end{array}$ & $\begin{array}{l}\text { CentralTemp } \\
\left({ }^{\circ}\right)\end{array}$ & $\begin{array}{l}\text { TempDiff } \\
\left({ }^{\circ}\right)\end{array}$ & $\begin{array}{l}\text { Distance } \\
\text { relationship } \\
(\mathrm{km})\end{array}$ & $\begin{array}{l}\text { Directional } \\
\text { relationship }\end{array}$ & $\begin{array}{l}\text { Topological } \\
\text { relationship }\end{array}$ & $\begin{array}{l}\text { Mean } \\
\text { Depth } \\
(\mathrm{m})\end{array}$ & \\
\hline Winter & Warm eddy & 0.09 & 0.7 & 151 & 23.31 & 0.03 & 77 & East & Disjoint & 2028 & $\mathrm{Z}_{2}$ \\
\hline Summer & Cold eddy & 0.18 & 1.0 & 201 & 29.94 & 0.08 & 20 & Southeast & Overlapping & 802 & $\mathrm{Z}_{4}$ \\
\hline$\ldots \ldots$ & $\cdots \cdots$ & $\ldots \ldots$ & $\ldots \ldots$ & $\ldots \ldots$ & $\ldots \cdots$ & $\ldots \ldots$ & $\ldots \ldots$ & $\ldots \ldots$ & $\ldots \ldots$ & $\ldots \ldots$ & $\ldots \ldots$ \\
\hline
\end{tabular}

Table 3. Decision table constructed from spatial-temporal relationships of mesoscale-eddy states in 4 seasons.

\begin{tabular}{|c|c|c|c|c|c|c|c|c|c|c|c|}
\hline \multicolumn{11}{|c|}{ Condition attribute } & \multirow{2}{*}{$\begin{array}{l}\begin{array}{l}\text { Decision } \\
\text { attribute }\end{array} \\
\text { Time }\end{array}$} \\
\hline $\begin{array}{l}\text { Origin } \\
\text { place }\end{array}$ & Type & $\begin{array}{l}\text { Intensity } \\
(\mathrm{m})\end{array}$ & $\begin{array}{l}\text { Vorticity } \\
\left(\times 10^{-5} \mathrm{~s}^{-1}\right)\end{array}$ & $\begin{array}{l}\text { Horizontal } \\
\text { Scale } \\
(\mathrm{km})\end{array}$ & $\begin{array}{l}\text { CentralTemp } \\
\left({ }^{\circ}\right)\end{array}$ & $\begin{array}{l}\text { TimeDiff } \\
\left({ }^{\circ}\right)\end{array}$ & $\begin{array}{l}\text { Distance } \\
\text { relationship } \\
(\mathrm{km})\end{array}$ & $\begin{array}{l}\text { Directional } \\
\text { relation- } \\
\text { ship }\end{array}$ & $\begin{array}{l}\text { Topological } \\
\text { relationship }\end{array}$ & $\begin{array}{l}\text { Mean } \\
\text { depth } \\
\text { (m) }\end{array}$ & \\
\hline $\mathrm{Z}_{1}$ & Warm eddy & 0.23 & 0.12 & 172 & 29.13 & 0.08 & 11 & North & Overlapping & 1757 & Autumn \\
\hline $\mathrm{Z}_{3}$ & Warm eddy & 0.12 & 0.07 & 196 & 28.65 & 1.42 & 26 & Northeast & Overlapping & 1712 & Winter \\
\hline$\ldots \ldots$ & $\ldots \ldots$ & $\ldots \ldots$ & $\ldots \ldots$ & $\ldots \ldots$ & $\ldots \ldots$ & $\ldots \ldots$ & $\ldots \ldots$ & $\ldots \ldots$ & $\ldots \ldots$ & $\ldots \ldots$ & $\ldots \ldots$ \\
\hline
\end{tabular}

Table 4. Decision table constructed from spatial-temporal relationships of the type of mesoscale eddies.

\begin{tabular}{|c|c|c|c|c|c|c|c|c|c|c|c|}
\hline \multicolumn{11}{|c|}{ Condition attribute } & \multirow{2}{*}{$\begin{array}{l}\begin{array}{l}\text { Decision } \\
\text { attribute }\end{array} \\
\text { Type }\end{array}$} \\
\hline $\begin{array}{l}\text { Origin } \\
\text { place }\end{array}$ & Time & $\begin{array}{l}\text { Intensity } \\
(\mathrm{m})\end{array}$ & $\begin{array}{l}\text { Vorticity } \\
\left(\times 10^{-5} \mathrm{~s}^{-1}\right)\end{array}$ & $\begin{array}{l}\text { Horizontal } \\
\text { Scale } \\
(\mathrm{km})\end{array}$ & $\begin{array}{l}\text { CentralTemp } \\
\left({ }^{\circ}\right)\end{array}$ & $\begin{array}{l}\text { TimeDiff } \\
\left({ }^{\circ}\right)\end{array}$ & $\begin{array}{l}\text { Distance } \\
\text { relation- } \\
\text { ship } \\
(\mathrm{km})\end{array}$ & $\begin{array}{l}\text { Directional } \\
\text { relation- } \\
\text { ship }\end{array}$ & $\begin{array}{l}\text { Topological } \\
\text { relation- } \\
\text { ship }\end{array}$ & $\begin{array}{l}\text { Mean } \\
\text { depth } \\
(\mathrm{m})\end{array}$ & \\
\hline $\mathrm{Z}_{2}$ & Autumn & 0.15 & 0.06 & 202 & 26.41 & 0.53 & 199 & East & Disjoint & 1645 & Warm eddy \\
\hline $\mathrm{Z}_{1}$ & Autumn & 0.27 & 0.11 & 194 & 28.58 & 0.23 & 43 & East & Overlapping & 1903 & Cold eddy \\
\hline$\ldots \ldots$ & $\ldots \ldots$ & $\ldots \ldots$ & $\ldots \ldots$ & $\ldots \ldots$ & $\ldots \ldots$ & $\ldots \ldots$ & $\ldots \ldots$ & $\ldots \ldots$ & $\ldots \ldots$ & $\ldots \ldots$ & $\ldots \ldots$ \\
\hline
\end{tabular}

12. Topological relationship (Topology) to the reference eddy, which can be represented by the RCC- 8 Model (Randell et al., 1992; Randell and Cohn, 1989) as disjoint or overlapping.

\section{Results}

\subsection{Attribute selection}

According to the methodology introduced in Sect. 2, the spatial-temporal relationship among mesoscale eddies in the SCS are described quantitatively by the twelve attributes specified in Sect. 2.2.3. They are discretised, if continuous, and then being imported into a decision table as condition attributes. A decision attribute is selected depending on the specific concern in each table, resulting in the minimal attribute reducts that are distinct according to the decision attribute. As a result, for each issue, rules extracted by rough set theory may be different. The place of origin of an eddy is selected as decision attribute in Table 2, in order to extract the corresponding rules from spatial-temporal relationships among eddies generated in all 4 zones of the SCS (Fig. 1). The generating season is selected as decision attribute in Table 3 , for investigating seasonal variation of the rules. And the type of eddy (warm/cold eddy) is selected as decision attribute in Table 4, where the rules between the two types of eddies are focused on.

In this study, quantitative indices of the twelve attributes depicting the total 391 typical states of 76 mesoscale eddies in the SCS are calculated by a Visual Basic Application (VBA) program running on the ArcGIS platform. The first three indices are used to be decision attributes and the others are condition attributes in decision tables. The Rosetta software (Qhrn, 1999), which is jointly developed by the Department of Computer and Information Science at Norwegian University of Science and Technology and Institute of Mathematics at University of Warsaw in Poland, is applied to calculate and extract rules once the decision table has been constructed. 
Table 5. Spatial-temporal rules extracted from typical mesoscaleeddy states in 4 zones of the SCS.

\begin{tabular}{|c|c|c|c|}
\hline No. & Spatial-temporal rule & $\begin{array}{l}\text { Certainty } \\
\text { level } \%\end{array}$ & $\begin{array}{l}\text { Coverage } \\
\text { level } \%\end{array}$ \\
\hline 1 & $\begin{array}{l}\text { Type }(\text { Cold Eddy) AND } \\
\text { Vorticity }\left(\left[0.7 \times 10^{-6}, *\right)\right) \text { AND } \\
\text { HorizontalScale }([*, 173)) \\
\text { AND CentralTemp }([*, 26.92)) \\
=>\operatorname{Zone}\left(Z_{1}\right)\end{array}$ & 100 & 15.5 \\
\hline 2 & $\begin{array}{l}\text { Time(Winter) AND } \\
\text { Type }(\text { Cold Eddy) AND } \\
\text { Vorticity }\left(\left[0.7 \times 10^{-6}, *\right)\right) \text { AND } \\
\text { CentralTemp }([*, 26.92)) \\
=>\operatorname{Zone}\left(Z_{1}\right)\end{array}$ & 100 & 14.3 \\
\hline 3 & $\begin{array}{l}\text { Type(Warm Eddy) AND } \\
\text { Intensity }([*, 0.08)) \text { AND } \\
\text { Vorticity }\left(\left[*^{*}, 0.7 \times 10^{-6}\right)\right) \text { AND } \\
\text { CentralTemp }([26.92,28.53)) \\
=>\operatorname{Zone}\left(Z_{3}\right)\end{array}$ & 100 & 13.3 \\
\hline 4 & $\begin{array}{l}\text { Time }(\text { Winter }) \text { AND Vortic- } \\
\text { ity }\left(\left[*, 0.7 \times 10^{-6}\right)\right) \text { AND } \\
\text { CentralTemp }([26.92,28.53)) \\
=>\operatorname{Zone}\left(Z_{3}\right)\end{array}$ & 100 & 13.3 \\
\hline 5 & $\begin{array}{l}\text { Time }(\text { Summer) AND } \\
\text { HorizontalScale }([195, *)) \\
\text { AND Depth }([900,2400]) \\
=>\text { Zone }\left(Z_{4}\right)\end{array}$ & 100 & 11.9 \\
\hline
\end{tabular}

Note: "[ ]" represents the closed interval, "( )" the open interval, "*” the infinite interval, as follows.

\subsection{Extraction of spatial-temporal rules of mesoscale eddies in the SCS}

Tables 5-7 show the corresponding spatial-temporal rules extracted from three decision tables (Tables 2-4), in which the decision-making attributes are place of origin, generating season and eddy type, respectively. All the rules have a coverage level of more than $10 \%$ and a certainty level of $100 \%$, respectively, being arrayed in descending order by coverage level. In all, 5 kinds of rules are extracted in Table 5, 11 in Table 6, and 13 in Table 7, respectively.

The typical eddy-states following all rules in Table 5 are detected and presented in Fig. 6 . There are two of five rules in zone $Z_{1}$ of the SCS, two in zone $Z_{3}, 1$ in zone $Z_{4}$ and none in zone $Z_{2}$, respectively. Cold-eddy states following Rule 1 are distributed southwest of Taiwan Island around $2000 \mathrm{~m}$ isobaths (zone $\mathrm{Z}_{1}$ ). It is obvious that most of the states follow both Rules 1 and 2 in this zone, except for one state following Rule 1 merely and one following Rule 2 merely. In $Z_{3}$ zone, all the states are in $4000 \mathrm{~m}$-and-deeper region of the basin, and follow both Rules 3 and 4 except one state following
Table 6. Spatial-temporal rules extracted from typical mesoscaleeddy states $\mathrm{s}$ in 4 seasons.

\begin{tabular}{|c|c|c|c|}
\hline No. & Spatial-temporal rule & $\begin{array}{l}\text { Confidence } \\
\text { level }(\%)\end{array}$ & $\begin{array}{l}\text { Coverage } \\
\text { Level (\%) }\end{array}$ \\
\hline 1 & $\begin{array}{l}\text { Zone }\left(Z_{2}\right) \text { AND } \\
\text { Type }(\text { Warm Eddy }) \text { AND } \\
\text { Vorticity }\left(\left[0.6 \times 10^{-6}, *\right)\right) \\
\left.\text { AND CentralTemp }\left({ }^{*}, 26.22\right)\right) \\
=>\text { Time }(\text { Winter })\end{array}$ & 100 & 32.5 \\
\hline 2 & $\begin{array}{l}\text { Zone }\left(Z_{2}\right) \text { AND Type }(\text { Warm } \\
\text { Eddy) AND CentralTemp([*, } \\
26.22)) \text { AND TempDiff([*, } \\
0.18))=>\text { Time(Winter) }\end{array}$ & 100 & 20.8 \\
\hline 3 & $\begin{array}{l}\text { Zone }\left(Z_{2}\right) \text { AND Central- } \\
\text { Temp }([*, 26.22)) \text { AND } \\
\text { Depth }([500,2800]) \\
=>\text { Time(Winter })\end{array}$ & 100 & 20.8 \\
\hline 4 & $\begin{array}{l}\text { CentralTemp }([*, 26.22)) \\
\text { AND TempDiff([*, 0.18)) } \\
\text { AND Depth([500,3000]) } \\
=>\text { Time(Winter })\end{array}$ & 100 & 20.0 \\
\hline 5 & $\begin{array}{llr}\text { Zone }\left(Z_{2}\right) & \text { AND } & \text { Type(Warm } \\
\text { Eddy }) \quad \text { AND Horizon- } \\
\text { talScale([147, 190)) AND } \\
\text { CentralTemp }\left(\left[{ }^{*}, 26.22\right)\right) \\
=>\text { Time(Winter) }\end{array}$ & 100 & 18.3 \\
\hline 6 & $\begin{array}{l}\text { Zone }\left(Z_{2}\right) \text { AND } \\
\text { Vorticity }\left(\left[0.06 \times 10^{-6}, *\right)\right) \\
\text { AND CentralTemp }([*, 26.22)) \\
\text { AND Topology }(\text { overlapping }) \\
=>\text { Time }(\text { Winter })\end{array}$ & 100 & 17.5 \\
\hline 7 & $\begin{array}{l}\text { Zone }\left(Z_{2}\right) \text { AND Type(Warm } \\
\text { Eddy) AND CentralTemp([*, } \\
\text { 26.22)) AND } \\
\text { Direction(Northeast) } \\
=>\text { Time(Winter) }\end{array}$ & 100 & 14.2 \\
\hline 8 & $\begin{array}{l}\text { Vorticity }\left(\left[0.06 \times 10^{-6}, *\right)\right) \\
\text { AND CentralTemp }([*, 26.22)) \\
\text { AND Topology }(\text { overlapping }) \\
\text { AND Depth }([500,4200)) \\
=>\text { Time }(\text { Winter })\end{array}$ & 100 & 13.3 \\
\hline 9 & $\begin{array}{l}\text { Zone }\left(Z_{2}\right) \text { AND Type }(\text { Warm } \\
\text { Eddy) AND Intensity }([0.16 \text {, } \\
*)) \text { AND CentralTemp }([26.22 \text {, } \\
28.72))=>\text { Time }(\text { Autumn })\end{array}$ & 100 & 11.7 \\
\hline 10 & $\begin{array}{l}\text { Zone }\left(Z_{4}\right) \quad \text { AND Central- } \\
\text { Temp }([29.59, *)) \text { AND } \\
\text { Distance }([19,42)) \\
=>\text { Time }(\text { Summer })\end{array}$ & 100 & 11.6 \\
\hline 11 & $\begin{array}{l}\text { Type(Warm Eddy) AND } \\
\text { CentralTemp }([29.59, *)) \text { AND } \\
\text { TempDiff([*, 0.18)) AND } \\
\text { Depth([2800, 4200]) } \\
=>\text { Time(Summer) }\end{array}$ & 100 & 11.6 \\
\hline
\end{tabular}


Table 7. Spatial-temporal rules extracted from typical states of two types of mesoscale eddy.

\begin{tabular}{|c|c|c|c|}
\hline No. & Spatial-temporal rule & $\begin{array}{l}\text { Confidence } \\
\text { level }(\%)\end{array}$ & $\begin{array}{l}\text { Coverage } \\
\text { Level }(\%)\end{array}$ \\
\hline 1 & $\begin{array}{l}\text { Vorticity }\left(\left[*, 0.7 \times 10^{-6}\right)\right) \\
\text { AND CentralTemp }([29.02, *)) \\
\text { AND Distance }([*, 48)) \\
=>\text { Type }(\text { Warm Eddy) }\end{array}$ & 100 & 22.3 \\
\hline 2 & $\begin{array}{l}\text { Vorticity }\left(\left[*, 0.7 \times 10^{-6}\right)\right) \\
\text { AND CentralTemp }([29.02, *)) \\
\text { AND Temp }([*, 0.16)) \\
=>\text { Type }(\text { Warm Eddy })\end{array}$ & 100 & 20.1 \\
\hline 3 & $\begin{array}{l}\text { Intensity }([0.17, *)) \text { AND } \\
\text { Vorticity }\left(\left[0.9 \times 10^{-6}, *\right)\right) \\
\text { AND Depth }([1400,2400]) \\
=>\text { Type }(\text { Cold Eddy })\end{array}$ & 100 & 17.3 \\
\hline 4 & $\begin{array}{l}\text { Time(Winter) AND } \\
\text { Depth([500,4400]) } \\
=>\text { Type(Warm Eddy) }\end{array}$ & 100 & 16.3 \\
\hline 5 & $\begin{array}{l}\text { Zone }\left(Z_{3}\right)=> \\
\text { Type(Warm Eddy) }\end{array}$ & 100 & 15.9 \\
\hline 6 & $\begin{array}{l}\text { Zone }\left(\mathrm{Z}_{4}\right) \text { AND Intensity } \\
([0.17, *)) \text { AND } \\
\text { Vorticity }\left(\left[0.9 \times 10^{-6}, *\right)\right) \\
=>\text { Type }(\text { Cold Eddy })\end{array}$ & 100 & 15.3 \\
\hline 7 & $\begin{array}{l}\text { Zone }\left(Z_{1}\right) \text { AND } \\
\text { Vorticity }\left(\left[0.9 \times 10^{-6}, *\right)\right) \\
\text { AND Depth }([1000,4200]) \\
=>\text { Type }(\text { Cold Eddy })\end{array}$ & 100 & 14.3 \\
\hline 8 & $\begin{array}{l}\text { Time }(\text { Autumn }) \text { AND } \\
\text { Vorticity }\left(\left[0.9 \times 10^{-6}, *\right)\right) \\
\text { AND Depth }([500,4200]) \\
\text { => Type }(\text { Cold Eddy })\end{array}$ & 100 & 14.3 \\
\hline 9 & $\begin{array}{l}\text { Intensity }([*, 0.10)) \text { AND } \\
\text { CentralTemp }([29.02, *)) \\
\text { AND Distance }([*, 48)) \\
=>\text { Type }(\text { Warm Eddy) }\end{array}$ & 100 & 13.8 \\
\hline 10 & $\begin{array}{l}\text { Vorticity }\left(\left[0.9 \times 10^{-6}, *\right)\right) \\
\text { AND CentralTemp }([27.72 \text {, } \\
29.02)) \text { AND Depth }([1000 \text {, } \\
4000])=>\text { Type }(\text { Cold Eddy })\end{array}$ & 100 & 13.3 \\
\hline 11 & $\begin{array}{l}\text { Zone }\left(\mathrm{Z}_{2}\right) \text { AND Time(Winter) } \\
\text { AND Distance }([*, 48)) \\
=>\text { Type(Warm Eddy) }\end{array}$ & 100 & 12.4 \\
\hline 12 & $\begin{array}{l}\text { CentralTemp }([*, 27.72)) \\
\text { AND Depth([1200,3600] }) \\
=>\text { Type }(\text { Cold Eddy })\end{array}$ & 100 & 12.2 \\
\hline 13 & $\begin{array}{l}\text { Time }(\text { Spring }) \text { AND } \\
\text { Vorticity }\left(\left[0.9 \times 10^{-6}, *\right)\right) \\
\text { AND Topology }(\text { Disjoint }) \\
=>\text { Type }(\text { Cold Eddy })\end{array}$ & 100 & 11.2 \\
\hline
\end{tabular}

Rule 3 only and one following Rule 4 only. There is a warm eddy southwest of Luzon Island besides the famous Luzon Cold Eddy, located northwest of Luzon Island.

Spatial-temporal rules extracted from typical mesoscaleeddy states occurring in the four seasons are presented in Table 6 . A total of 8 rules are extracted in winter, 2 in summer, 1 in fall and none in spring, respectively. Spatial distribution of the states following all 11 rules is shown in Fig. 7a in winter, $7 \mathrm{~b}$ in summer and $7 \mathrm{c}$ in fall. No eddy state is extracted in spring. As Fig. 7a shows, all the states, in winter, are concentrated around the western $2000 \mathrm{~m}$ isobaths of the northern basin (both zones $Z_{1}$ and $Z_{2}$ ) with an exception of one state in the basin center (zone $Z_{3}$ ). There are many more states of eddies in winter than the other seasons.

In Fig. 7a, two states obey Rules 1 and 2 together in zone $Z_{2}$. Another two obey Rules 2 and 3 together in zone $Z_{2}$. These four states are located in the eastern Paracel Island, maybe originating from the Xisha Warm Eddy AE1 in D. Wang et al. (2008). Two states obey Rules 6 and 7 together: one in zone $Z_{1}$, another in zone $Z_{2}$. Furthermore, several eddy states obey three rules together, including two obeying Rules 1, 6 and 7 together in zone $Z_{2}$, which maybe originates from Warm Eddy AE1 detected by D. Wang et al. (2008), and three obeying Rules 2, 6 and 7 together on the boundary of zone $\mathrm{Z}_{2}$ towards zone $\mathrm{Z}_{1}$, which maybe originate from another Warm Eddy AE2 detected by D. Wang et al. (2008). Three states obey Rules 4 and 8 together in zone $\mathrm{Z}_{1}$. In addition, four obey Rules 2,3 and 8 together in zone $Z_{2}$, and two states obey four rules (Rules 1, 3, 6 and 7) together in zone $\mathrm{Z}_{2}$.

In summer, the typical states of eddies become less obvious, as shown in Table 6. Most of the states, in Fig. 7b, are distributed around the western $2000 \mathrm{~m}$ isobaths with one exception in the central basin (zone $\mathrm{Z}_{3}$ ). There are two clusters of eddy states off the Vietnam coast, eight states over the shelf of northern Vietnam $(<2000 \mathrm{~m})$, and seven in the $2000 \mathrm{~m}$ and deeper region off southern Vietnam in zone $\mathrm{Z}_{4}$. Only two obey both summer rules together, one is in shallow water off northern Vietnam coast, the other is in deep water off southern Vietnam Peninsula. Besides, there are three warm-eddy states located in north of the basin, the boundary of zones $Z_{1}$ and $Z_{2}$. NLOM displaces the wind jet flow northwards to $13-14^{\circ} \mathrm{N}$ (compared with the observed location $10.5-11^{\circ} \mathrm{N}$ ) so that the two clusters are distributed either side of $14^{\circ} \mathrm{N}$.

In fall, all ten eddy states are around the western boundary of $2000 \mathrm{~m}$ isobaths of the northern basin (zone $\mathrm{Z}_{2}$ ) exclusively, as shown in Fig. 7c, one half are in north of the zone, the other half in the south. This season has the least eddy states annually. These states form four clusters. Two of them are off west Luzon Strait, another two are composed by 4 states off the southeast of Hainan Island.

Spatial-temporal rules extracted from two types of typical eddy states (warm/cold eddy) are shown in Table 7. A total of 6 rules (Rules 1, 2, 4, 5, 9 and 11) are extracted for 

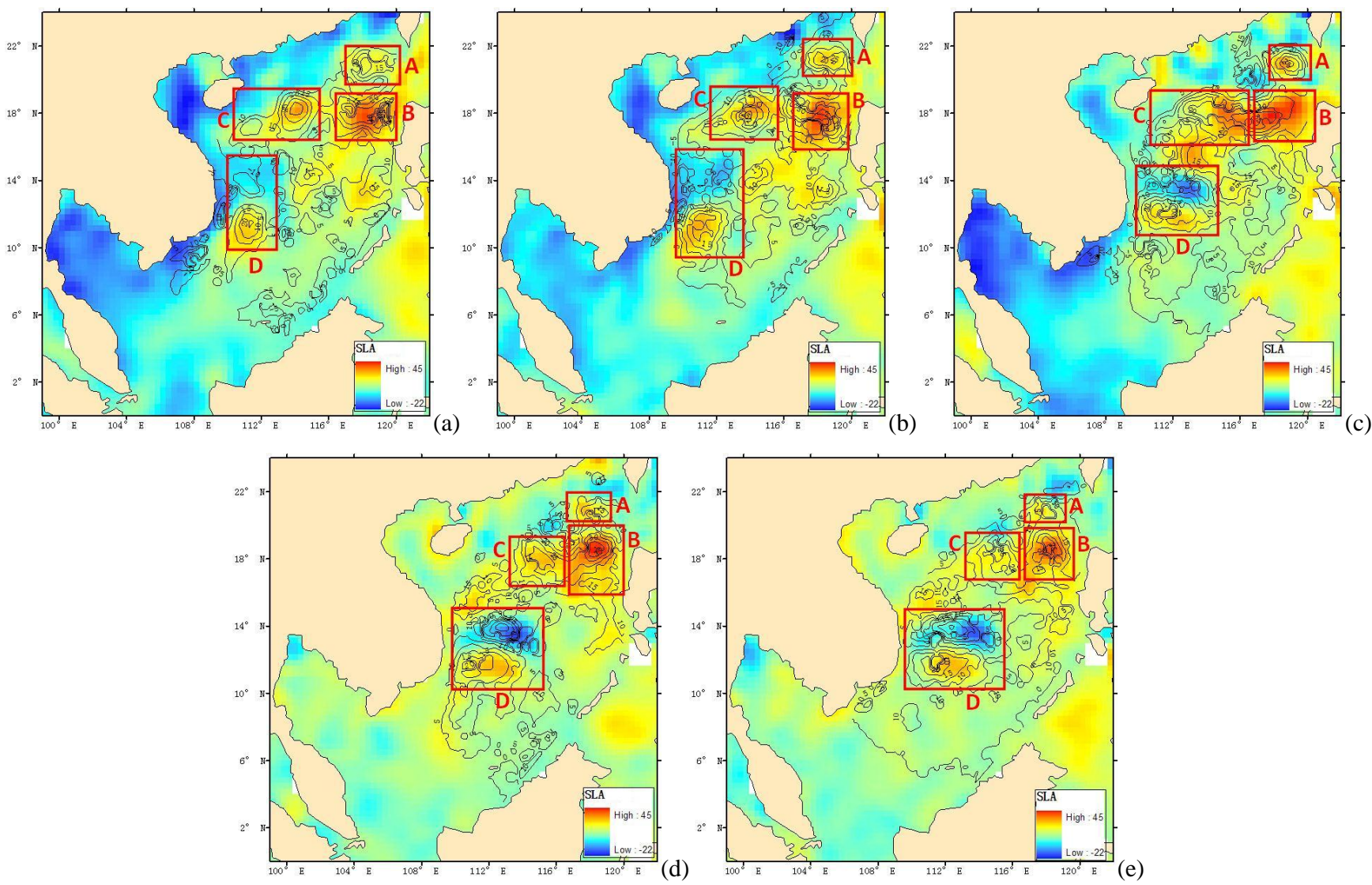

Fig. 5. Comparison of 5-days NLOM SSHA contours with AVISO SLA image in the SCS. Four deterministic eddies are marked as Warm Eddy off the Luzon Strait (red capital A), the West Luzon Eddy (red capital B), the Warm Eddy near Xisha Island (red capital C) and the Eddy Pair Offshore from Vietnam (red capital D).

warm-eddy states, and 7 rules (Rules 3, 6, 7, 8, 10, 12 and 13) for cold-eddy states. Spatial distribution of cold-eddy states is shown in Fig. 8a and warm-eddy states in Fig. 8b.

All cold-eddy states are distributed as a band along the western $2000 \mathrm{~m}$ isobaths (Fig. 8a) from west of Luzon Strait to the southeast of Hainan Island, and to offshore of Vietnam; they are also revealed recently by both model and satellite data (Xiu et al., 2010). In zone $Z_{1}$, two cold-eddy states obey Rules 7 and 13 together in spring, five obey Rules 7 and 8 together in fall and two obey Rules 12 and 13 together in spring, other than one cold-eddy state obeys Rules 7, 8 and 10 together in fall. Figure 8 a also shows that the states following Rule 3 seldom exist southwest of Taiwan Island. In zone $Z_{2}$, one cold-eddy state obeys Rules 7 and 13 together. Three obey Rule 13 in spring, and one obeys Rule 12. None is in zone $Z_{3}$. In zone $Z_{4}$, two clusters of states are separated by the wind jet along $13-14^{\circ} \mathrm{N}$. Four cold-eddy states following Rule 12 are located at the northern wind jet. Six cold-eddy states follow Rules 6 and 8 together in fall, being distributed on each side of the jet as parts of the two clusters, respectively. And one state follows Rules 6, 8 and 10 together in fall on the southern side of the jet flow.
Figure $8 \mathrm{~b}$ shows that typical warm-eddy states are more numerous than cold eddy states, and distributed as two strips: one is around the western $2000 \mathrm{~m}$ isobaths, another is NESW in the deeper region of the abyssal basin west of Luzon Island. They occupy all 4 zones of the SCS, especially in the south. Rule 1 indicates general features of numerous warmeddy states in the SCS, which are distributed predominantly offshore from Vietnam and west of Luzon Island. Most of states obeying Rule 4 appear in north of western $2000 \mathrm{~m}$ isobaths. The others are southwest of Luzon Island, named the West Luzon Eddy by Qu (2000). Several warm-eddy states obey Rules 1 and 9 together. One is located in zone $Z_{1}$, the others in zones $Z_{2}-Z_{4}$. Two states obey Rule 1 together with Rule 11 , of which one is in zone $Z_{1}$ and the other in zone $Z_{2}$. Furthermore, in zone $Z_{2}$, two states obey Rules 1 and 5 together, and several obey Rules 1,9 and 11 together. In zone $Z_{3}$ several states obey Rules 4 and 5 together, and two obey Rules 1, 5 and 9 together. Two obey Rules 1, 2 and 9 together in zone $\mathrm{Z}_{4}$. 


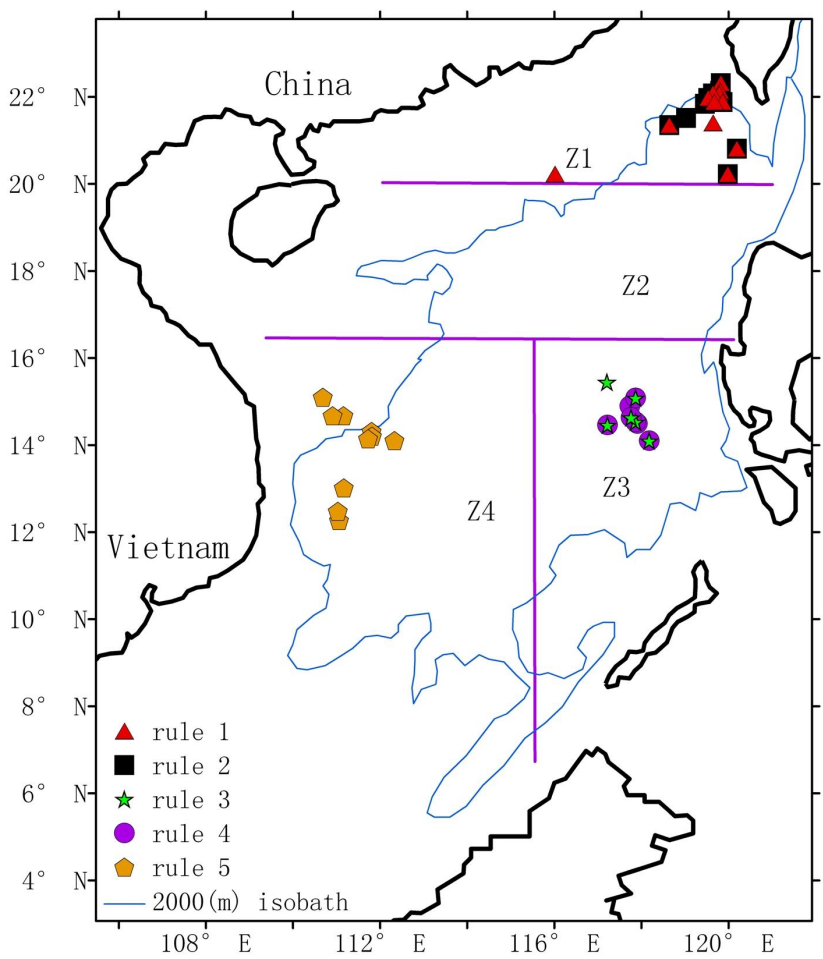

Fig. 6. Spatial distribution of typical mesoscale-eddy states in the SCS extracted from Table 5. (Blue line is $2000 \mathrm{~m}$ isobaths.)

\section{Discussion}

Orographic wind is induced by the Cordillera on the southwest of Taiwan Island in winter. It makes cold water in the subsurface upwelling and forms a cold-eddy core due to the Ekman pumping effect (Qu, 2000). Thus, cold-eddy states on the northeastern tip of $2000 \mathrm{~m}$ isobaths in Fig. 6 may be induced by this orographic wind stress curl. G. Wang et al. (2008) reveal that the winter gap winds in the mountainous island chain along the eastern boundary of the SCS are intrinsic regional features of the monsoon due to orographic effects, spinning up cold and warm eddies west of Luzon Island. In summer, the eddy pair offshore from Vietnam induced by a wind jet, as is well known, has the same attributes in horizontal scale and the water depth of eddy core (Rule 5 in Table 5).

In winter, the Kuroshio intrusion plays a major role on mesoscale eddies in the northern SCS (e.g. Su, 2004; Wu and Chiang, 2007; Zhuang et al., 2010). Frontal instability at the Kuroshio intrusion could be one mechanism in eddy shedding (Wang et al., 2000; Su, 2004). In Fig. 7a, a certain warm-eddy states have the possibility to be shed from the Kuroshio meander near west of Luzon Strait. Several previous studies conclude that, off central Vietnam, there is a cyclonic gyre north of about $12^{\circ} \mathrm{N}$, but an anti-cyclonic gyre to the south (Kuo et al., 2000; Xie et al., 2003). Accompanying these gyres is a northward orographic wind jet turning offshore from the Vietnam coast near $12^{\circ} \mathrm{N}$. In Fig. $7 \mathrm{~b}$, the typical warm-eddy states are distributed not only south of the jet flow induced by intraseasonal wind stress, but also in the northern shallow water; it is unclear how eddy is generated; this should be a focus of future study. In Fig. 7c, the south partition seems to derive from two warm eddies AE1 and AE2 near Paracel Island in D. Wang et al. (2008).

All of cold-eddy states appear in spring and fall, neither summer nor winter, and they converge on the northern tip of the basin and west of Luzon Strait, as shown in Fig. 8a; they are induced by wind stress curl resulting from the blockage effect of Cordillera on the southwest of Taiwan Island $(\mathrm{Qu}$, 2000; $\mathrm{Su}, 2004$ ) or the net water transport into the SCS via the Luzon strait (Su, 2004). Lack of a cold-eddy rule in winter, may result from the rules' coverage level being less than $10 \%$, not indicative of no cold eddy at all. In zone $\mathrm{Z}_{4}$, the cold-eddy states located at both northern and southern sides of the Vietnam jet flow only occur in fall. Wind forcing plays a major role in their generation (Zhuang et al, 2010). Four cold-eddy states obey Rules 6 and 13 together in spring, located only on the southern wind jet off the Vietnam coast. It is unclear why a cold eddy occurs in this season, and no previous study focuses on this question. Oceanographers should pay more attention to this phenomenon in future study. In Fig. 8b, the two-strip distribution is in good agreement with the spatial pattern achieved by both model and satellite observations (Xiu et al., 2010) and total eddy energy achieved by the intraseasonal variability of SSH (Zhuang et al., 2010). In winter the Kuroshio intrusion induces warm eddies west of Luzon Strait and their evolution, and the Dongsha warm current induces frontal warm eddies (Su, 2004) near Pratas Island. Wind forcing converges on the upper-layer warm water and downwells under the Ekman pumping effect (Qu, 2000). Downwelling brings warm water from surface to the deep creating warm core eddies such as the West Luzon Eddy. Eddy states following Rules 4 and 5 in Table 7 off southwestern Luzon Island are considered as being induced by the interaction between strong barotropic shelf currents and the local topography (Xiu et al., 2010). There is no warm-eddy state in the northern tip of $2000 \mathrm{~m}$ isobaths (southwest of Taiwan Island or west of Luzon Strait), as is clear in Fig. 8a, maybe due to lack of negative wind stress curl.

There is a phenomenon that some typical mesoscale-eddy states follow two rules or more in Figs. 6-8, respectively, indicating they have much stronger regularity in spatialtemporal distribution. From the above analysis, we find that the typical cold-eddy states located southwest of Taiwan Island, namely the northeastern tip of the basin, appear in winter (Fig. 6). The typical warm-eddy states are distributed either southwest of Luzon Island, the deepest region of the basin, or the western edge of $2000 \mathrm{~m}$ isobaths. It is shown in Table 7 that no rule can be co-followed by the two types of eddies.

Lots of previous works on mesoscale eddies in the SCS have been performed by in situ measurement, numerical 

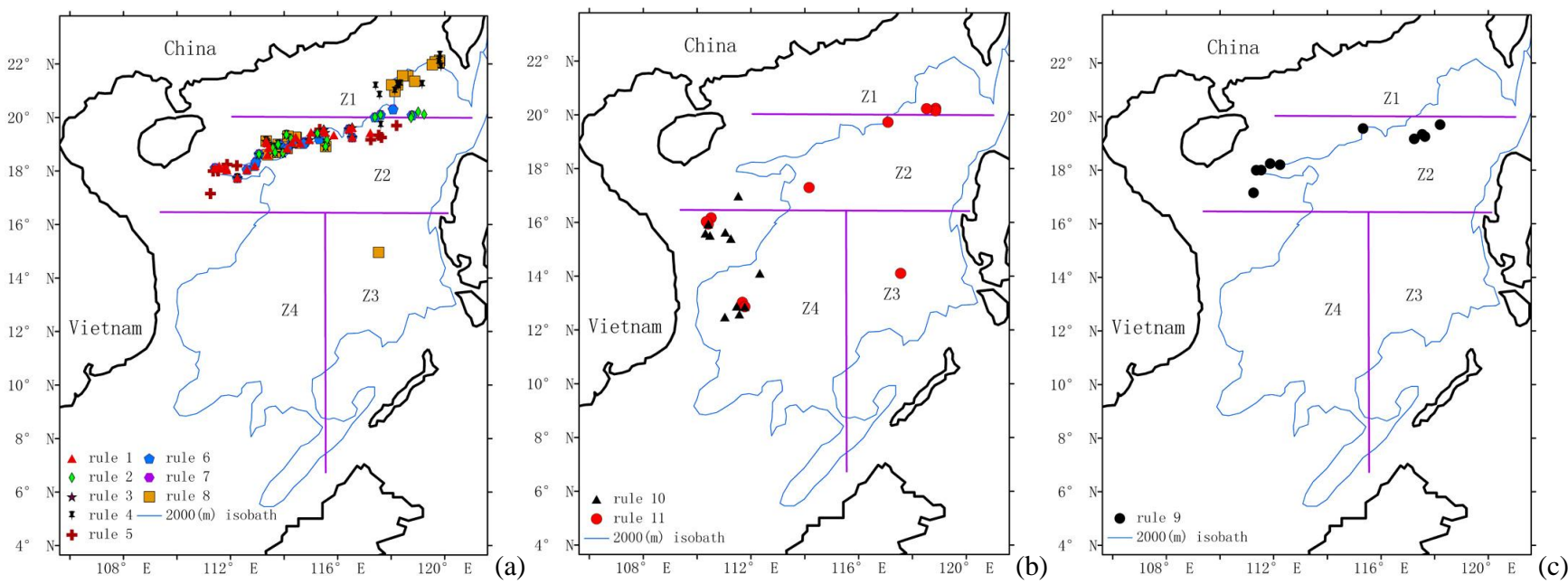

Fig. 7. Spatial distributions of typical states of two types of mesoscale eddy in (a) winter, (b) summer and (c) fall in the SCS extracted from Table 6. No state is extracted in spring. (Blue line is $2000 \mathrm{~m}$ isobaths.)
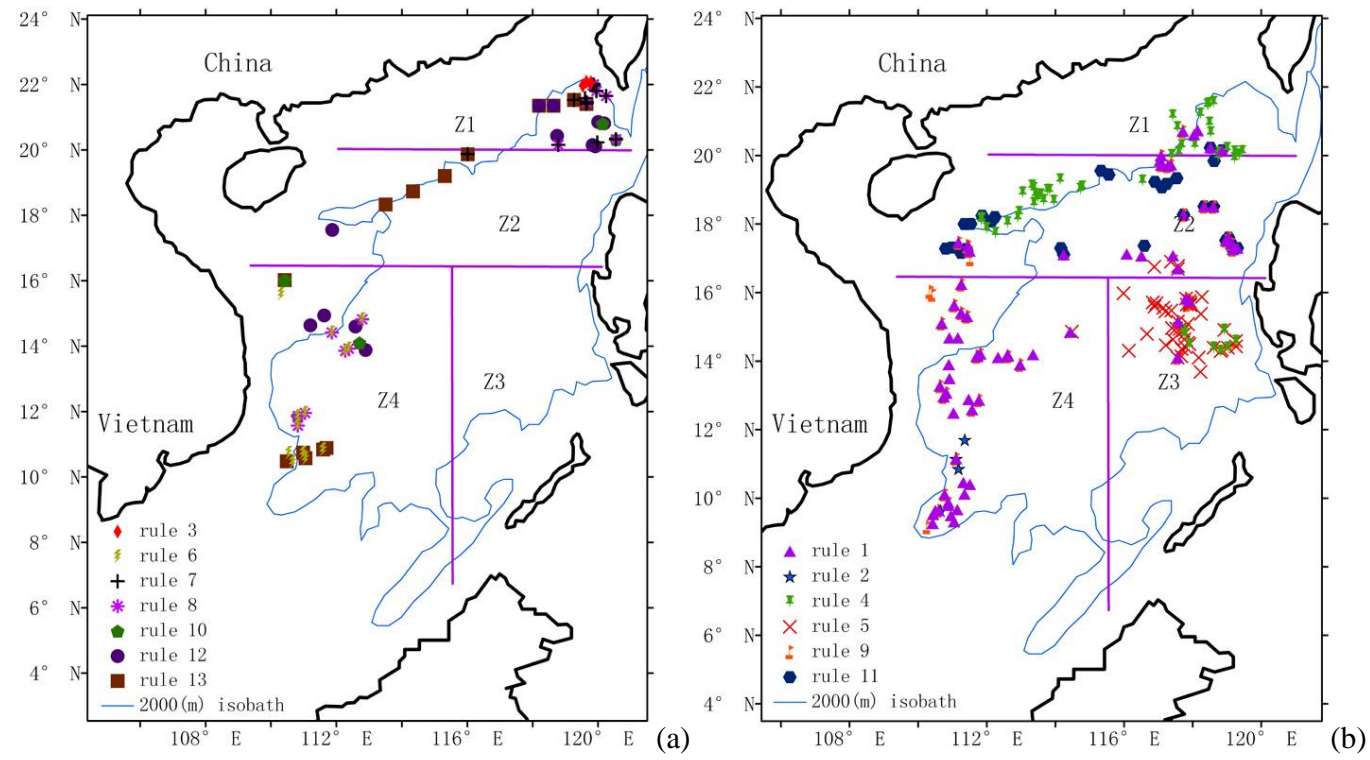

Fig. 8. Spatial distribution of all typical (a) cold-eddy states and (b) warm-eddy states in the SCS extracted from Table 7. (Blue line is $2000 \mathrm{~m}$ isobaths.)

simulation and satellite observation. Some of their conclusions can be replicated in our study, as the following examples:

1. Through analyzing 5-yr T/P data, Wang et al. (2000) point out that mesoscale eddies in the SCS are active along the western $2000 \mathrm{~m}$ isobaths and the NE-SW oriented band from south of Luzon Strait to $11^{\circ} \mathrm{N}$ around the eastern Vietnam Peninsula. This is also revealed by Lin et al. (2007) through statistical analysis of 10-yr T/P data and Wang (2004) through statistical analysis of 8$\mathrm{yr}$ T/P data. In our study this spatial feature of eddies is confirmed one more time, as shown in Fig. 8b. In this Figure, warm-eddy states are located in the NWSE oriented band, which confirms the conclusion in Lin et al. (2007) that there are warm eddies in the region $\left(14-15^{\circ} \mathrm{N}, 118-120^{\circ} \mathrm{E}\right)$ exclusively, but no cold eddy occurs.

2. Cheng et al. (2005) conclude that warm eddies are distributed north of $18^{\circ} \mathrm{N}$, which is followed by Rule 1, 2, 5 and 7 in Table 5 and Rule 11 in Table 6. In Fig. 8b, these states are in the western zone $\mathrm{Z}_{2}\left(18-20^{\circ} \mathrm{N}\right)$.

3. Most mesoscale eddies appear off the eastern Vietnam Peninsula, the western Luzon Strait and in the 
northeastern SCS, while they are inactive in the southeastern SCS (e.g. Wang, 2004; Lin et al., 2007; Cheng et al., 2005). This is confirmed in Fig. 6.

4. D. Wang et al. (2008) examine warm eddies AE1 and AE2 in the northeastern SCS during the winter of 20032004. We can confirm that the six states of eddy AE1 in Figs. 2 and 4 of D. Wang et al. (2008) follow Rules 1 and 3 together in Table 5 and Rules 4 and 11 together in Table 6, while none of rules is followed by states of eddy AE2. AE2 locates in zone $Z_{1}$, as shown in Fig. 6 . No rule can be extracted among warm-eddy states in this zone in winter other than Rule 1 of Table 6 . It should be pointed out that we are not able to obtain the Euclidean distance, directional relationship and topological relationship of the two eddies. Thus only some of rules in Tables 4-6 could be confirmed by D. Wang et al. (2008).

However, there are several features achieved in our study that were not paid enough attention in previous works. In winter, warm eddies, as is well known, are generated in the northeastern SCS resulting from the frequent Kuroshio intrusion, thus most oceanographers focus on their generating mechanism, evolving process, and so on. Whereas, a few rules extracted in this zone are followed by cold eddies in winter, indicating cold eddies may be well-regulated in the region. Meanwhile, west of Luzon Island, the famous Luzon cold eddy is focused. Several rules, however, are achieved for warm eddies in this zone, indicating warm eddies may be well-regulated in the region as well. Otherwise, warm eddies are distributed not only on the jet flow off southern Vietnam induced by intraseasonal wind stress in summer-fall, but also on the northern shallow water, which should be a focus of future study. Similarly, cold eddies are also located at both northern and southern sides of the Vietnam jet flow in fall. And there are cold eddies generated off southern Vietnam in spring. These are interesting but no studies have been carried out; we suggest that these eddies should be studied.

Otherwise, the approach requires to select the corresponding spatial-temporal relationships among mesoscale eddies according to each issue. It is also worth noting that the raw data used in this study is derived from numerical modeling. Some eddies with a shorter life-time or smaller horizontal scale may not be included, as a result of not being identified. So the number of eddies analyzed is fewer than the actual total. In the future, the rough set approach will be improved by supplementing data acquired in different sea areas and seasons into the database, selecting appropriate attribute factors that can better reflect spatial-temporal relationships among eddies, and applying other discretization and reducts algorithms based on rough set theory. Comparison of the results derived from different scenarios would help yield more practically significant rules.

\section{Conclusions}

In this paper, a rough set theory is introduced to represent spatial-temporal relationships and extract the corresponding rules from typical mesoscale-eddy states in the SCS. These rules clearly confirm spatial-temporal distribution patterns and features of these states. Three decision attributes are adopted in this study, which make the approach flexible in retrieving spatial-temporal rules with different features. The results demonstrate that this approach is effective, and therefore provides a powerful approach to forecasts in future studies. Spatial-temporal rules in the SCS indicate that warm eddies following the rules are generally in the southeastern and central SCS around $2000 \mathrm{~m}$ isobaths in winter. Their intensity and vorticity are weaker than those of cold eddies. They usually move a shorter distance. By contrast, cold eddies are in $2000 \mathrm{~m}$ and deeper regions of the southwestern and northeastern SCS in spring and fall. Their intensity and vorticity are strong. Usually they move a long distance. In winter, a few rules are followed by cold eddies in the northern tip of the basin and southwest of Taiwan Island rather than warm eddies, indicating cold eddies may be well-regulated in the region. Several warm-eddy rules are achieved west of Luzon Island, indicating warm eddies may be well-regulated in the region as well. Otherwise, warm and cold eddies are distributed not only in the jet flow off southern Vietnam induced by intraseasonal wind stress in summer-fall, but also in the northern shallow water, which should be a focus of future study.

Acknowledgements. This work was fully supported by the National Science Fund (project Number: 41071250), and the National 863 High Technology Programs of China (Project No. 2011BAH23B04), and was granted from an independent innovation project of State Key Laboratory of Resource and Environment Information System, CAS (Project No. 088RA500KA). The authors appreciate comments from reviewers and readers.

Edited by: J. M. Huthnance

\section{References}

Bai, H., Ge, Y., Wang, J., and Liao, Y.: Using rough set theory to identify villages affected by birth defects: the example of Heshun, Shanxi, China, Int. J. Geogr. Inf. Sci., 24, 559-576, 2010.

Cheng, X., Qi, Y., and Wang, W.: Seasonal and Interannual Variabilities of Mesoscale Eddies in South China Sea, J. Trop. Oceanogr., 24, 51-59, 2005.

Fang, G., Chen, H., Wei, Z., Wang, Y., Wang, X., and Li, C.: Trends and interannual variability of the South China Sea surface winds, surface height, and surface temperature in the recent decade, J. Geophys. Res. 111, C11S16, doi:10.1029/2005JC003276, 2006.

Fayyad, U. M. and Irani, K. B.: On the handling of continuousvalued attributes in decision tree generation, Mach. Learn., 8, 87-102, 1992.

Fayyad, U. M. and Irani, K. B.: Multi-interval discretization of continuous-valued attributes for classification learning, 
Proceedings of the 13th International Joint Conference on Artificial Intelligence, IJCAI-93, 1993.

He, Z., Wang, D., and Hu, J.: Features of eddy kinetic energy and variations of upper circulation in the South China Sea, Acta Oceanol. Sinica, 21, 305-314, 2002 (in Chinese with English abstract).

Hetland, R. H., Hsueh, Y., Leben, R. R., and Niiler, P. P.: A loop current-induced jet along the edge of the West Florida shelf, Geophys. Res. Lett., 26, 2239-2242, 1999.

Hu, J., Kawamura, H., Hong, H., Kobashi, F., and Wang, D.: 3-6 months variation of sea surface height in the South China Sea and its adjacent ocean, J. Oceanogr., 57, 69-78, 2001.

Hurlburt, H. E. and Thompson, J. D.: A numerical study of loop current intrusions and eddy shedding, J. Phys. Oceanogr., 10, 1611-1651, 1980.

Hwang, C., Wu, C. R., and Kao, R.: TOPEX/Poseidon observations of mesoscale eddies over the Subtropical Counter Current: kinematic characteristics of an anticyclonic eddy and a cyclonic eddy, J. Geophys. Res., 109, C08013, doi:10.1029/2003JC002026, 2004.

Jia, Y. and Liu, Q.: Eddy shedding from the Kuroshio bend at Luzon Strait, J. Oceanogr., 60, 1063-1069, 2004.

Jia, Y., Liu, Q., and Liu, W.: Primary studies of the mechanism of eddy shedding from the Kuroshio bend in Luzon Strait, J. Oceanogr., 61, 1017-1027, 2005.

Komorowski, J., Pawlak, Z., Polkowski, L., and Skowron, A.: Rough sets: A tutorial, in: Rough fuzzy hybridization: a new trend in decision-making, edited by: Pal, S. and Skowron, A., Singapore, Springer-Verlag, 3-93, 1999.

Kuo, N. J., Zheng, Q., and Ho, C. R.: Satellite observation of upwelling along the western coast of the South China Sea, Remote Sens. Environ., 74, 463-470, 2000.

Leung, Y. and Li, D.: Maximal consistent block technique for rule acquisition in incomplete information systems, Inf. Sci., 153, 85$106,2003$.

Li, L.: A review on mesoscale oceanographical phenomena in the South China Sea, J. Oceanogr. Taiwan, 21, 265-274, 2002 (in Chinese with English abstract).

Li, L. and Wu, B.: A Kuroshio loop in South China Sea?, J. Oceanogr. Taiwan, 8, 89-95, 1989 (in Chinese with English abstract).

Li, L., Nowlin Jr., W. D. and Su, J.: Anticyclonic rings from the Kuroshio in the South China Sea, Deep-Sea Res. Pt. I 45, 1469 1482, 1998

Lin, P., Wang, F., Chen, Y., and Tang, X.: Temporal and spatial variation characteristics on eddies in the South China Sea I. Statistical analyses, Acta Oceanol. Sinica, 29, 14-22, 2007.

Liu, Q., Jiang, X., Xie, S., and Liu, W.: A gap in the Indo-Pacific warm pool over the South China Sea in boreal winter: Seasonal development and interannual variability, J. Geophys. Res., 109, C07012, doi:10.1029/2003JC002179, 2004.

Metzger, E. J. and Hurlburt, H. E.: The nondeterministic nature of Kuroshio penetration and eddy shedding in the South China Sea, J. Phys. Oceanogr., 31, 1712-1732, 2001.

Miao, D. and Li, D.: Rough Sets Theory Algorithms and Applications, TsingHua University Press, Beijing, 2008.

Nguyen, H. S. and Skowron, A.: Quantization of real-valued attributes, in: Proceeding 2nd International Joint Conference on Information Sciences, Wrightsville Beach, NC, 34-37, 1995.
Pawlak, Z.: Rough sets, Int. J. Parallel. Prog., 11, 341-356, 1982.

Pawlak, Z.: Rough Sets: Theoretical Aspects of Reasoning about Data, Kluwer Academic Publishers, Boston, 1991.

Pawlak, Z.: Bayes' theorem revised- the rough set view, in: Proceedings of International Workshop on Rough Set Theory and Granular Computing (RSTGC 2001), Matshue, Shimane, Japan, $1-8,2001$

Polkowski, L. and Skowron, A.: Rough Sets in Knowledge Discovery 1: Methodology and Applications, 2: Applications, PhysicaVerlag, Heidelberg, 1998.

Polkowski, L., Tsumoto, S., and Lin, T.: Rough Set Methods and Applications, Physica-Verlag, Heidelberg, 49-88, 2000.

Qhrn, A.: Discernibility and rough sets in medicine: tools and application, Norwegian University of Science and Technology, Norway, 41-51, 1999.

Qu, T.: Upper-layer circulation in the South China Sea, J. Phys. Oceanogr., 30, 1450-1460, 2000.

Randell, D. A. and Cohn, A. G.: Modelling topological and metrical properties in physical processes, in: Proceedings of the 1st International Conference on the Principles of Knowledge Representation and Reasoning, Morgan Kaufmann Publishers, San Francisco, 55-66, 1989.

Randell, D. A., Cui, Z., and Cohn, A. G.: A spatial logic based on regions and connection, in: Proceedings of the 3rd International Conference on Principles of Knowledge Representation and Reasoning, Morgan Kaufmann Publishers, San Francisco, 165-176, 1992.

Roemmich, D. and Gilson, J.: Eddy transport of heat and thermocline waters in the North Pacific: a key to interannual/decadal climate variability, J. Phys. Oceanogr., 31, 675-687, 2001.

Skowron, A.: Synthesis of adaptive decision systems from experimental data, in: Proceedings of the Fifth Scandinavian Conference on Artificial Intelligence, number 28 in Frontiers in Artificial Intelligence and Applications, edited by: Aamodt, A. and Komorowski, J., IOS Press, 220-238, 1995.

Skowron, A.: Rough sets and Boolean reasoning, in: Granular Computing: An Emerging Paradigm, edited by: Pedrycz, W., Physica-Verlag, Heidelberg, 95-124, 2001.

$\mathrm{Su}$, J.: Overview of the South China Sea circulation and its influence on the coastal physical oceanography outside the Pearl River Estuary, Cont. Shelf Res., 24, 1745-1760, 2004.

Su, J., Lu, J., Hou, Y., Fang, G., Wei, Z., and Yin, B.: Analysis of satellite-tracked drifting buoys in the South China Sea, Oceanol. Limnol. Sinica, 33, 121-127, 2002 (in Chinese with English abstract).

Wang, D., Xu, H., Lin, J., and Hu, J.: Anticyclonic eddies in the northeastern South China Sea during winter 2003/2004, J. Oceanogr., 64, 925-935, 2008.

Wang, G.: Discussion on the Movement of Mesoscale Eddies in the South China Sea, Ph.D. Dissertation, Ocean University of China, Qingdao, 2004.

Wang, G., Su, J., and Chu, P.: Mesoscale eddies in the South China Sea observed with altimeter data, Geophys. Res. Lett., 30, 2121, doi:10.1029/2003GL018532, 2003.

Wang, G., Chen, D., and Su, J.: Generation and life cycle of the dipole in the South China Sea summer circulation, J. Geophys. Res., 111, C06002, doi:10.1029/2005JC003314, 2006.

Wang, G., Chen, D., and Su, J.: Winter eddy genesis in the Eastern South China Sea due to orographic wind jets, J. Phys. Oceanogr., 
38, 726-732, doi:10.1175/2007JPO3868.1, 2008.

Wang, G. Y.: Rough Set Theory and Knowledge Acquisition, Xi'an: Xi' an Jiaotong University Press, 2001 (in Chinese).

Wang, L., Koblinsky, C. J., and Howden, S.: Mesoscale variability in the South China Sea from the TOPEX/Poseidon altimetry data, Deep-Sea Res Pt. I, 47, 681-708, 2000.

White, W. B.: Tropic coupled Rossby waves in the Pacific oceanatmosphere system, J. Phys. Oceanogr., 30, 1245-1264, 2000.

Wu, C. and Chang, C. W. J.: Interannual variability of the South China Sea in a data assimilation model, Geophys. Res. Lett., 32, L17611, doi:10.1029/2005GL023798, 2005.

Wu, C. and Chiang, T.: Mesoscale eddies in the northern South China Sea, Deep-Sea Res. Pt. II, 54, 1575-1588, 2007.

Wu, C., Tang, T., and Lin, S.: Intra-seasonal variation in the velocity field of the northeastern South China Sea, Cont. Shelf Res., 25, 2075-2083, 2005.

Wyrtki, K.: Physical oceanography of the southeast Asian waters, NAGA report, Vol. 2, Scientific results of marine investigation of the South China sea and the Gulf of Thailand, Scripps Institution of Oceanography, La Jolla, Calif., 195 pp., 1961.

Xie, S., Xie, Q., Wang, D., and Liu, W.: Summer upwelling in the South China Sea and its role in regional climate variations, J. Geophys. Res., 108, 3261, doi:10.1029/2003JC001867, 2003.

Xiu, P., Chai, F., Shi, L., Xue, H., and Chao, Y.: A census of eddy activities in the South China Sea during 1993-2007, J. Geophys. Res., 115, C03012, doi:10.1029/2009JC005657, 2010.
Xu, X., Qiu, Z., and Chen, H.: The general descriptions of the horizontal circulation in the South China Sea, in: Proceedings of the 1980 Symposium on Hydrometeorology, Chinese Society of Oceanology and Limnology, Science Press, Beijing, 137-145, 1982.

Yang, K., Shi, P., Wang, D., and Qi, Y.: Numerical study about the mesoscale multi-eddy system in the northern South China Sea in winter, Acta Oceanol. Sinica, 22, 27-34, 2000 (in Chinese with English abstract).

Yasdi, R.: Combining rough sets learning and neural learning: method to deal with uncertain and imprecise information, Neuralcomputing, 7, 61-84, 1996.

Yuan, D., Han, W., and Hu, D.: Surface Kuroshio path in the Luzon Strait area derived from satellite remote sensing data, J. Geophys. Res., 111, C11007, doi:10.1029/2005JC003412, 2006.

Yuan, D., Han, W., and Hu, D.: Anti-cyclonic eddies northwest of Luzon in summer-fall observed by satellite altimeters, Geophys. Res. Lett., 34, L13610, doi:10.1029/2007GL029401, 2007.

Yuan, S. Y. and Wang, Z. Z.: Topography forced Rossby waves in the section from Xisha to Dongsha Islands, Trop. Oceanol., 5, 1-6, 1986 (in Chinese with English abstract).

Zhuang, W., Xie, S., Wang, D., Taguchi, B., Aiki, H., and Sasaki, H.: Intraseasonal variability in sea surface height over the South China Sea, J. Geophys. Res., 115, C04010, doi:10.1029/2009JC005647, 2010. 